\title{
Acanthopleuribacter pedis gen. nov., sp. nov., a marine bacterium isolated from a chiton, and description of Acanthopleuribacteraceae fam. nov., Acanthopleuribacterales ord. nov., Holophagaceae fam. nov., Holophagales ord. nov. and Holophagae classis nov. in the phylum 'Acidobacteria'
}

Correspondence Yukiyo Fukunaga fukunaga-yukiyo@nite.go.jp
Yukiyo Fukunaga, ${ }^{1,2}$ Midori Kurahashi, ${ }^{2}$ Kensuke Yanagi, $^{3}$ Akira Yokota $^{2}$ and Shigeaki Harayama ${ }^{1}$

\author{
${ }^{1}$ NITE Biological Resource Center (NBRC), National Institute of Technology and Evaluation (NITE), \\ 2-5-8 Kazusa-Kamatari, Kisarazu-shi, Chiba 292-0818, Japan \\ ${ }^{2}$ Institute of Molecular and Cellular Biosciences, University of Tokyo, 1-1-1 Yayoi, Bunkyo-ku, Tokyo \\ 113-0032, Japan \\ ${ }^{3}$ Coastal Branch, Natural History Museum and Institute, 123 Yoshio, Katsuura, Chiba 299-5242, \\ Japan
}

\begin{abstract}
Strain FYK2218 ${ }^{\top}$ was isolated from a specimen of the chiton Acanthopleura japonica, which had been collected from a beach on the Boso peninsula in Japan. Phylogenetic analyses based on 16S rRNA gene sequences revealed that the strain belonged to the phylum 'Acidobacteria'. The most closely related type strains to strain FYK2218 ${ }^{\top}$ were Holophaga foetida $\mathrm{TMBS}^{\top}$ (83.6\% 16S rRNA gene sequence similarity) and Geothrix fermentans $\mathrm{H}-5^{\top}$ (83.6\%) in subdivision 8 of the 'Acidobacteria'. Cells of FYK2218' were motile, rod-shaped, Gram-negative, mesophilic and strictly aerobic. The $\mathrm{G}+\mathrm{C}$ content of the strain was $56.7 \mathrm{~mol} \%$. The strain had isoprenoid quinones MK- 6 and MK-7 as major components. Major fatty acids of the strain were iso- $\mathrm{C}_{15: 0 \text {, }}$ iso- $\mathrm{C}_{17: 0}, \mathrm{C}_{16: 0}$ and $\mathrm{C}_{20: 5} \omega 3 \mathrm{c}$ (cis-5,8,11,14,17-eicosapentaenoic acid). From the taxonomic data obtained in this study, it is proposed that the new marine isolate be placed into a novel genus and species named Acanthopleuribacter pedis gen. nov., sp. nov. within the new family, order and class Acanthopleuribacteraceae fam. nov., Acanthopleuribacterales ord. nov. and Holophagae classis nov. The family Holophagaceae fam. nov. is also described. The type strain of Acanthopleuribacter pedis is FYK2218 ${ }^{\top}\left(=\right.$ NBRC $\left.101209^{\top}=\mathrm{KCTC}_{12899^{\top}}\right)$.
\end{abstract}

Culture-independent studies based on the detection of $16 \mathrm{~S}$ rRNA gene sequences have shown that bacteria belonging to the phylum 'Acidobacteria' are ubiquitous in various environments including fresh water, a hot spring microbial mat (Barns et al., 1999), sewage sludge (Layton et al., 2000) and desert soils (Chanal et al., 2006). The range of divergence in 16S rRNA gene sequences among members of the 'Acidobacteria' was almost 20\% (Quaiser et al., 2003), indicating that this phylum is as diverse as Proteobacteria (Barns et al., 1999). In terms of validly published names, the phylum 'Acidobacteria' contains a

The DDBJ/GenBank/EMBL accession number for the 16S rRNA gene sequence of Acanthopleuribacter pedis FYK2218 ${ }^{\top}$ is AB303221.

Transmission electron micrographs of strain $\mathrm{FYK} 2218^{\top}$, a $16 \mathrm{~S}$ rRNA gene sequence-based tree and a detailed fatty acid profile of strain FYK2218 are available as supplementary material with the online version of this paper. single class, Acidobacteria, and a single order, Acidobacteriales (Cavalier-Smith, 2002), consisting of the genera Acidobacterium (Kishimoto et al., 1991), Holophaga (Liesack et al., 1994) and Geothrix (Coates et al., 1999). However, eight monophyletic subdivisions are currently recognized in the phylum 'Acidobacteria' based on rRNA sequence approaches (Hugenholtz et al., 1998). Thus, although a few strains belonging to the phylum 'Acidobacteria' have since been isolated from soils (Janssen et al., 2002; Joseph et al., 2003), several groups in the phylum 'Acidobacteria' remain uncultured.

We have reported that marine invertebrates are interesting sources for the discovery of novel lineages of bacteria (Fukunaga et al., 2006; Kurahashi \& Yokota, 2002, 2004). Here, we describe a novel strain isolated from a chiton 
which was classified by its $16 \mathrm{~S}$ rRNA gene sequence to be a member of the phylum 'Acidobacteria'.

In 2003, a chiton (Acanthopleura japonica) was collected from a Pacific Ocean beach near the Natural History Museum and Institute at Katsuura, located on the Boso peninsula, Chiba, Japan. The chiton was washed with sterile artificial seawater (ASW; Naigai Chemical Products) and dissected. The dissected tissues were homogenized separately using a hand-held homogenizer. Subsequently, the chiton homogenates were serially diluted 10 -fold in sterile ASW and suitable dilutions were plated onto 1/5strength marine agar 2216 (Difco). The plates were incubated at $20{ }^{\circ} \mathrm{C}$ for 8 days and colonies that grew were purified on the same medium. Strain FYK2218 ${ }^{\mathrm{T}}$ was isolated from the foot tissue of the chiton.

Colonies of the strain were circular, entire, smooth and yellow in colour. Phase-contrast microscopy showed that cells of the strain grown on marine broth 2216 (Difco) are motile. Cells were negatively stained with phosphotungstic acid and observed under a transmission electron microscope (Hitachi H7600). Electron micrographs showed that the cells were rod-shaped $(0.7-1.0 \times 2.4-4.7 \mu \mathrm{m})$ and peritrichously flagellated (Supplementary Fig. S1a, available in IJSEM Online). For the preparation of ultrathin sections, cells of FYK $2218^{\mathrm{T}}$ were processed by rapid freezing in liquid propane cooled with liquid nitrogen, cryosubstituted with $2 \%(\mathrm{w} / \mathrm{v}) \mathrm{OsO}_{4}$ in acetone for 3 days and embedded in epoxy resin. Ultrathin sections were double-stained with a platinum-blue staining solution (Inaga et al., 2007) (using threefold-diluted stock solution) for $10 \mathrm{~min}$ and a lead staining solution (Reynolds, 1963) for $1 \mathrm{~min}$. Ultrathin sectioning revealed a typical Gramnegative cell wall structure (Supplementary Fig. S1b), which was further confirmed with the $3 \%(\mathrm{w} / \mathrm{v}) \mathrm{KOH}$ reaction (Buck, 1982).

The DNA G $+\mathrm{C}$ content of strain FYK $2218^{\mathrm{T}}$ was determined by HPLC analysis (Mesbah et al., 1989) to be $56.7 \mathrm{~mol} \%$. Extraction of cellular fatty acids from cells grown for $48 \mathrm{~h}$ at $25{ }^{\circ} \mathrm{C}$ on marine agar and determination of the fatty acid content by GC were carried out using the Microbial Identification (MIDI) System (MIDI Laboratories) according to the manufacturer's instructions. Fatty acids not identified by the MIDI System where further analysed using GC-MS (Agilent). The cellular fatty acid profile of strain FYK $2218^{\mathrm{T}}$ is shown in Supplementary Table S1. The major fatty acids in FYK $2218^{\mathrm{T}}$ were iso- $\mathrm{C}_{15: 0}$ (19.0\% of the total fatty acids), iso- $\mathrm{C}_{17: 0}(14.1 \%), \mathrm{C}_{16: 0}$ $(12.5 \%)$ and $\mathrm{C}_{20.5} \omega 3 c(7.9 \%)$. Hydroxy fatty acids in FYK $2218^{\mathrm{T}}$ were iso- $\mathrm{C}_{13: 0} 3-\mathrm{OH}(5.7 \%)$ and iso- $\mathrm{C}_{17: 0} 3-$ $\mathrm{OH}(3.4 \%)$. Isoprenoid quinones were extracted from dry cells with chloroform/methanol $(2: 1, \mathrm{v} / \mathrm{v})$, dried under a nitrogen stream and analysed by LC-MS [Shimadzu model LC-5A equipped with an ODS-II column $(2.0 \times 150 \mathrm{~mm}$; Shinwa Chemical Industries)] using methanol/isopropyl ether $(2: 1, \mathrm{v} / \mathrm{v})$ as mobile phase. The respiratory quinones were menaquinones MK-6 (57.8\%) and MK-7 (42.2\%).
Physiological and biochemical tests were performed by using API 20NE and API ZYM kits (both from bioMérieux) and Biolog GN2 microtitre plates according to the manufacturers' specifications except that cells of FYK $2218^{\mathrm{T}}$ were suspended in a sterile solution as suggested by Rüger \& Krambeck (1994). In the Biolog GN2 tests, 8 of 95 carbon sources were oxidized by strain FYK $2218^{\mathrm{T}}$. The results of the API ZYM, API20NE and Biolog GN2 tests are listed in the description of the novel species.

Tests for anaerobic growth were conducted on either M9 minimal medium plates (Sambrook \& Russell, 2001) containing $0.2 \%(\mathrm{w} / \mathrm{v})$ glucose and $1.5 \%(\mathrm{w} / \mathrm{v}) \mathrm{NaCl}$ or marine agar at $25{ }^{\circ} \mathrm{C}$ in a GasPak anaerobic jar (Becton Dickinson). Growth of strain FYK $2218^{\mathrm{T}}$ on M9 or marine agar plates was not observed under anaerobic conditions.

Salt tolerance was tested with R2A agar (Difco) suspended in ASW $(0-200 \%, v / v)$ and the plates were incubated at $25{ }^{\circ} \mathrm{C}$. Growth was observed on R2A agar containing 50$150 \%$ ASW, with optimal growth at 70-120\% ASW. To test the $\mathrm{pH}$ range for growth, $20 \mu \mathrm{l}$ cell suspension was transferred to test tubes containing $5 \mathrm{ml}$ filter-sterilized TYSW ( $2 \mathrm{~g}$ tryptone and $1 \mathrm{~g}$ yeast extract dissolved in $1 \mathrm{l}$ ASW) at $\mathrm{pH} 1-11$ and incubated at $25^{\circ} \mathrm{C}$. Strain FYK $2218^{\mathrm{T}}$ grew in TYSW at initial $\mathrm{pH}$ between 5.0 and 9.0. The optimum $\mathrm{pH}$ for growth was $\mathrm{pH}$ 7.0-8.0. To test the temperature range for growth, marine agar plates were incubated at $4,10,15,20,25,30,35,37,40$ or $45^{\circ} \mathrm{C}$ for 7 days. Strain FYK $2218^{\mathrm{T}}$ grew at $15-30{ }^{\circ} \mathrm{C}$, but did not grow at 10 or $35{ }^{\circ} \mathrm{C}$. Optimum growth occurred at $30{ }^{\circ} \mathrm{C}$.

The 16S rRNA gene was analysed as described by Fukunaga et al. (2006). The 16S rRNA gene sequence of strain FYK2218 ${ }^{\mathrm{T}}$ was aligned with related sequences using CLUSTAL_X (Thompson et al., 1997). Phylogenetic trees were inferred by using neighbour-joining (NJ; Saitou \& Nei, 1987), maximum-parsimony (MP; Swofford, 2000) and maximum-likelihood (ML; Adachi \& Hasegawa, 1996) algorithms. The topology of the trees was calculated by bootstrap resampling analysis (Felsenstein, 1985) of 1000 replicates for NJ and MP and local bootstrap probabilities (Hasegawa \& Kishino, 1994) of 100 replicates for ML.

The results of an initial BLAST search showed a cloned sequence from coral (GenBank accession no. EF206921; Koren \& Rosenberg, 2006) to be the closest relative of strain FYK2218 ${ }^{\mathrm{T}}$, with a $16 \mathrm{~S}$ rRNA gene sequence similarity of $93.3 \%$. Phylogenetic trees inferred from NJ, MP and ML algorithms based on 1262 and $667 \mathrm{bp}$, respectively, of the $16 S$ rRNA gene sequence are shown in Fig. 1 and Supplementary Fig. S2. Strain FYK $2218^{\mathrm{T}}$ forms a distinct clade in the radiation of subdivision 8 of the 'Acidobacteria' (Fig. 1 and Supplementary Fig. S2), supported by high bootstrap values. The most closely related species to strain FYK $2218^{\mathrm{T}}$ were Holophaga foetida $(83.6 \%$ identity to the type strain) and Geothrix fermentans ( $83.6 \%$ identity). The results of the phylogenetic analysis are supported by the phenotypic differences of strain $\mathrm{FYK} 2218^{\mathrm{T}}$ from Holophaga foetida and other phylogenetic neighbours 


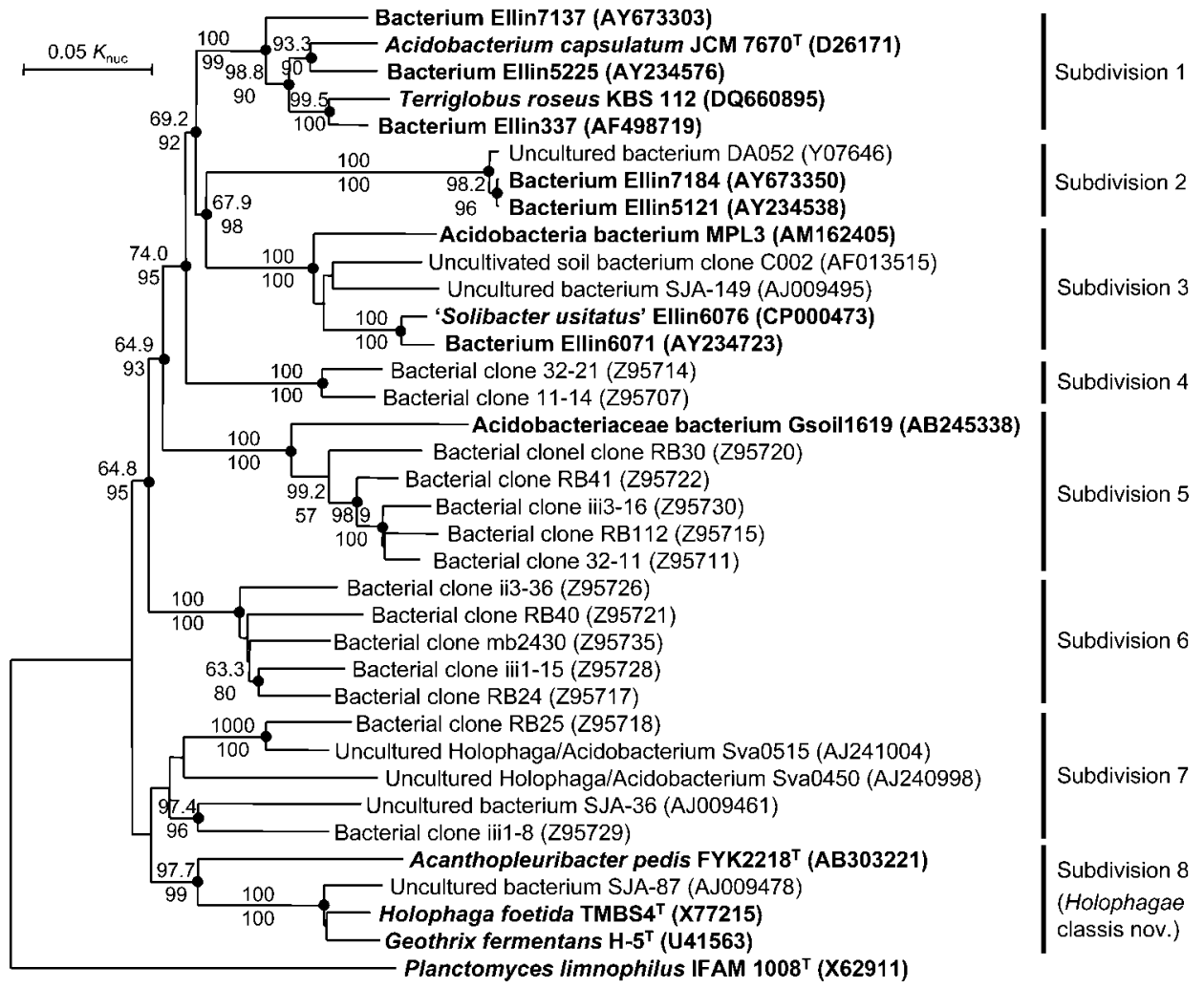

Fig. 1. Neighbour-joining tree of the phylum 'Acidobacteria' based on $16 \mathrm{~S}$ rRNA gene sequences using 1262 bp. Cultivated strains are shown in bold. Branch points supported by NJ, ML and MP analysis are indicated by solid circles. Bootstrap values above $50 \%$ are shown (above the nodes, NJ; below, ML).

Table 1. Differential characteristics of FYK2218 ${ }^{\top}$ and members of related genera in subdivision 8 of the phylum 'Acidobacteria'

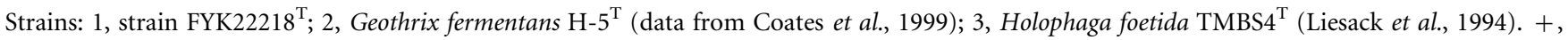
Positive; -, negative; ND, no data available.

\begin{tabular}{|c|c|c|c|}
\hline Characteristic & 1 & 2 & 3 \\
\hline Pigmentation & Yellow & White & Translucent-beige \\
\hline Motility & + & - & - \\
\hline Optimum pH & $7.0-8.0$ & ND & $6.8-7.5$ \\
\hline Aerobic growth & + & - & - \\
\hline Glucose & + & - & ND \\
\hline Acetate & - & + & ND \\
\hline Propionate & - & + & ND \\
\hline Succinate & - & + & - \\
\hline Pyruvate & - & $\mathrm{ND}$ & + \\
\hline Fructose & - & ND & - \\
\hline
\end{tabular}


(Table 1). Based on these results, we conclude that strain FYK $2218^{\mathrm{T}}$ represents a new genus and species in subdivision 8 of 'Acidobacteria', for which the name Acanthopleuribacter pedis gen. nov., sp. nov. is proposed.

In phylogenetic trees obtained with the NJ, MP and ML algorithms, the cluster of subdivision 8 in the 'Acidobacteria' including FYK $2218^{\mathrm{T}}$ was independent and was supported by high bootstrap values (Fig. 1). Furthermore, levels of $16 \mathrm{~S}$ rRNA gene sequence similarity between FYK $2218^{\mathrm{T}}$ and other members of subdivision 8 of the 'Acidobacteria' were very low (82.7-83.6\%). It is therefore also proposed that subdivision 8 of the phylum 'Acidobacteria' should be classified not in the class Acidobacteria and order Acidobacteriales (Cavalier-Smith, 2002) but as a new class, Holophagae classis nov., with two new orders, Acanthopleuribacterales ord. nov. and Holophagales ord. nov. Order Acanthopleuribacterales contains the new family Acanthopleuribacteraceae fam. nov., with Acanthopleuribacter as its type genus. The genus Holophaga is placed in a new family Holophagaceae fam. nov. in the order Holophagales.

\section{Description of Acanthopleuribacter gen. nov.}

Acanthopleuribacter (A.can'tho.pleu.ri.bac'ter. N.L. n. Acanthopleura a zoological genus name of shellfish; N.L. masc. n. bacter a rod; N.L. masc. n. Acanthopleuribacter a rod from Acanthopleura, referring to the isolation of the first strain from the chiton Acanthopleura japonica).

Cells are Gram-negative, motile, strictly aerobic rods. Predominant fatty acids are iso- $\mathrm{C}_{15: 0}$, iso- $\mathrm{C}_{17: 0}$ and $\mathrm{C}_{16: 0}$, while the major hydroxy fatty acids are iso- $\mathrm{C}_{13: 0} 3-\mathrm{OH}$ and iso- $\mathrm{C}_{17: 0}$ 3-OH. MK-6 and MK-7 are the menaquinones. The $\mathrm{G}+\mathrm{C}$ content of the genomic DNA of the type strain of the type species is $56.7 \mathrm{~mol} \%$. The type species is Acanthopleuribacter pedis.

\section{Description of Acanthopleuribacter pedis sp. nov.}

Acanthopleuribacter pedis (pe'dis. L. gen. n. pedis of the foot, referring to the isolation of the type strain from the foot of a chiton).

In addition to the characteristics listed for the genus, the following are observed. Cells are $0.7-1.0 \times 2.4-4.7 \mu \mathrm{m}$ and motile by peritrichous flagella. Colonies on marine agar are circular, smooth and yellow in colour. Grows on marine agar at $15-30{ }^{\circ} \mathrm{C}$ (optimally at $30{ }^{\circ} \mathrm{C}$ ). Grows at pH 5.0-9.0 (optimally at pH 7.0-8.0). Growth is observed on R2A agar supplemented with 50-150\% ASW (optimally with 70$120 \%$ ASW). Catalase and oxidase activities are present. Nitrate and nitrite are not reduced, acid is not produced from glucose and indole is not produced from tryptophan. $\beta$-Glucosidase and protease activities are present. Arginine dihydrolase and urease activities are not detected. Growth by fermenting glucose under anaerobic conditions is not observed. The following substrates are utilized for growth: $\alpha$-D-glucose, L-alanine, hydroxy-L-proline, L-serine,
L-threonine, inosine, uridine and thymidine. Activities in the API ZYM strip are detected for alkaline phosphatase, leucine arylamidase, valine arylamidase, trypsin, acid phosphatase, naphthol-AS-BI-phosphohydrolase and $\mathrm{N}$ acetyl- $\beta$-glucosaminidase. Tests for esterase $\mathrm{C} 4$, ester lipase $\mathrm{C} 8$, cystine arylamidase and $\beta$-glucosidase are weakly positive. Activities of lipase C4, chymotrypsin, $\alpha$-galactosidase, $\beta$-galactosidase, $\beta$-glucuronidase, $\alpha$-glucosidase, $\alpha$ mannosidase and $\alpha$-fucosidase are not observed. The quinone system of the type strain consists of MK-6 (57.8\%) and MK-7 (42.2\%).

The type strain, FYK $2218^{\mathrm{T}}\left(=\mathrm{NBRC} 101209^{\mathrm{T}}=\mathrm{KCTC}\right.$ $12899^{\mathrm{T}}$ ), was isolated from a chiton, Acanthopleura japonica, from the Boso peninsula, Japan.

\section{Description of Acanthopleuribacteraceae fam. nov.}

Acanthopleuribacteraceae (A.can'tho.pleu.ri.bac'te.ra'ce.ae. N.L. masc. n. Acanthopleuribacter type genus of the family; -aceae ending to donate a family; N.L. fem. pl. n. Acanthopleuribacteraceae the family of the genus Acanthopleuribacter).

The description is the same as that for the genus Acanthopleuribacter. The family contains the type genus Acanthopleuribacter.

\section{Description of Acanthopleuribacterales ord. nov.}

Acanthopleuribacterales (A.can'tho.pleu.ri.bac'te.ra'les. N.L. masc. n. Acanthopleuribacter type genus of the order; -ales ending to denote an order; N.L. fem. pl. n. Acanthopleuribacterales the order of genus Acanthopleuribacter).

The description is the same as that for the genus Acanthopleuribacter. The order contains the family Acanthopleuribacteraceae. The type genus is Acanthopleuribacter.

\section{Description of Holophagaceae fam. nov.}

Holophagaceae (Ho.lo.pha.ga'ce.ae. N.L. fem. n. Holophaga type genus of the family; -aceae ending to donate a family; N.L. fem. pl. n. Holophagaceae the family of the genus Holophaga).

Defined by phylogenetic analyses based on 16S rRNA gene sequences. The family contains the genera Holophaga (Liesack et al., 1994) and Geothrix (Coates et al., 1999). The type genus is Holophaga.

\section{Description of Holophagales ord. nov.}

Holophagales (Ho.lo.pha.ga'les. N.L. fem. n. Holophaga type genus of the order; -ales ending to denote an order; N.L. fem. pl. n. Holophagales the order of genus Holophaga). 
The description is the same as for the family Holophagaceae. The order contains the family Holophagaceae. The type genus is Holophaga.

\section{Description of Holophagae classis nov.}

Holophagae (Ho.lo.pha'gae. N.L. fem. pl. n. Holophagales type order of the class; -ae ending to denote a class; N.L. fem. pl. n. Holophagae the class of the order Holophagales).

Equivalent to subdivision 8 (Hugenholtz et al., 1998) of the phylum 'Acidobacteria' and is defined by phylogenetic analyses based on 16S rRNA gene sequences obtained from three cultured representatives and a wide range of uncultured bacteria retrieved mainly from marine and soil habitats. Gram-negative. The class comprises the orders Holophagales and Acanthopleuribacterales. The type order is Holophagales.

\section{Acknowledgements}

We are grateful to Dr Jean P. Euzéby (École Nationale Vétérinaire de Toulouse) for his help in the latinization of the new names. We thank Motoyuki Ohuchi, Naomi Noguchi, Maiko Torii and Kozue Anzai (NITE) for their help with determination of chemotaxonomic characters and DNA sequencing. Many thanks for help with TEM observation to Dr Kenji Tanaka and Kaoru Yamaguchi. This work was supported by a grant from the New Energy and Industrial Technology Development Organization, Japan (P02038).

\section{References}

Adachi, J. \& Hasegawa, M. (1996). MOLPHY Version 2.3 - Programs for Molecular Phylogenetics Based on Maximum Likelihood. Computer Science Monograph no. 28. Tokyo: Institute of Statistical Mathematics.

Barns, S. M., Takala, S. L. \& Kuske, C. R. (1999). Wide distribution and diversity of members of the bacterial kingdom Acidobacterium in the environment. Appl Environ Microbiol 65, 1731-1737.

Buck, J. D. (1982). Nonstaining (KOH) method for determination of Gram reactions of marine bacteria. Appl Environ Microbiol 44, 992993.

Cavalier-Smith, T. (2002). The neomuran origin of archaebacteria, the negibacterial root of the universal tree and bacterial megaclassification. Int J Syst Evol Microbiol 52, 7-76.

Chanal, A., Chapon, V., Benzerara, K., Barakat, M., Christen, R., Achouak, W., Barras, F. \& Heulin, T. (2006). The desert of Tataouine: an extreme environment that hosts a wide diversity of microorganisms and radiotolerant bacteria. Environ Microbiol 8, 514-525.

Coates, J. D., Ellis, D. J., Gaw, C. V. \& Lovley, D. R. (1999). Geothrix fermentans gen. nov., sp. nov., a novel $\mathrm{Fe}(\mathrm{III})$-reducing bacterium from a hydrocarbon-contaminated aquifer. Int J Syst Bacteriol 49, 1615-1622.

Felsenstein, J. (1985). Confidence limits on phylogenies: an approach using the bootstrap. Evolution 39, 783-791.

Fukunaga, Y., Kurahashi, M., Tanaka, K., Yanagi, K., Yokota, A. \& Harayama, S. (2006). Pseudovibrio ascidiaceicola sp. nov., isolated from ascidians (sea squirts). Int J Syst Evol Microbiol 56, 343-347.

Hasegawa, M. \& Kishino, H. (1994). Accuracies of the simple methods for estimating the bootstrap probability of a maximumlikelihood tree. Mol Biol Evol 11, 142-145.
Hugenholtz, P., Goebel, B. M. \& Pace, N. R. (1998). Impact of culture-independent studies on the emerging phylogenetic view of bacterial diversity. J Bacteriol 180, 4765-4774.

Inaga, S., Katsumoto, T., Tanaka, K., Kameie, T., Nakane, H. \& Naguro, T. (2007). Platinum blue as an alternative to uranyl acetate for staining in transmission electron microscopy. Arch Histol Cytol 70, 43-49.

Janssen, P. H., Yates, P. S., Grinton, B. E., Taylor, P. M. \& Sait, M. (2002). Improved culturability of soil bacteria and isolation in pure culture of novel members of the divisions Acidobacteria, Actinobacteria, Proteobacteria, and Verrucomicrobia. Appl Environ Microbiol 68, 2391-2396.

Joseph, S. J., Hugenholtz, P., Sangwan, P., Osborne, C. A. \& Janssen, P. H. (2003). Laboratory cultivation of widespread and previously uncultured soil bacteria. Appl Environ Microbiol 69, 7210-7215.

Kishimoto, N., Kosako, Y. \& Tano, T. (1991). Acidobacterium capsulatum gen. nov., sp. nov.: an acidophilic chemoorganotrophic bacterium containing menaquinone from acidic mineral environment. Curr Microbiol 22, 1-7.

Koren, O. \& Rosenberg, E. (2006). Bacteria associated with mucus and tissues of the coral Oculina patagonica in summer and winter. Appl Environ Microbiol 72, 5254-5259.

Kurahashi, M. \& Yokota, A. (2002). A preliminary report of phylogenetic diversity of bacterial strains isolated from marine creatures. J Gen Appl Microbiol 48, 251-259.

Kurahashi, M. \& Yokota, A. (2004). Agarivorans albus gen. nov., sp. nov., a $\gamma$-proteobacterium isolated from marine animals. Int J Syst Evol Microbiol 54, 693-697.

Layton, A. C., Karanth, P. N., Lajoie, C. A., Meyers, A. J., Gregory, I. R., Stapleton, R. D., Taylor, D. E. \& Sayler, G. S. (2000). Quantification of Hyphomicrobium populations in activated sludge from an industrial wastewater treatment system as determined by $16 \mathrm{~S}$ rRNA analysis. Appl Environ Microbiol 66, 1167-1174.

Liesack, W., Bak, F., Kreft, J. U. \& Stackebrandt, E. (1994). Holophaga foetida gen. nov., sp. nov., a new, homoacetogenic bacterium degrading methoxylated aromatic compounds. Arch Microbiol 162, 85-90.

Mesbah, M., Premachandran, U. \& Whitman, W. B. (1989). Precise measurement of the $\mathrm{G}+\mathrm{C}$ content of deoxyribonucleic acid by highperformance liquid chromatography. Int J Syst Bacteriol 39, 159-167.

Quaiser, A., Ochsenreiter, T., Lanz, C., Schuster, S. C., Treusch, A. H., Eck, J. \& Schleper, C. (2003). Acidobacteria form a coherent but highly diverse group within the bacterial domain: evidence from environmental genomics. Mol Microbiol 50, 563-575.

Reynolds, E. S. (1963). The use of lead citrate at high $\mathrm{pH}$ as an electron-opaque stain in electron microscopy. J Cell Biol 17, 208-212.

Rüger, H.-J. \& Krambeck, H.-J. (1994). Evaluation of the BIOLOG substrate metabolism system for classification of marine bacteria. Syst Appl Microbiol 17, 281-288.

Saitou, N. \& Nei, M. (1987). The neighbor-joining method: a new method for reconstructing phylogenetic trees. Mol Biol Evol 4, 406-425.

Sambrook, J. \& Russell, D. W. (2001). Molecular Cloning: a Laboratory Manual, 3rd edn. Cold Spring Harbor, NY: Cold Spring Harbor Laboratory.

Swofford, D. L. (2000). PAUP*: Phylogenetic analysis using parsimony (* and other methods), version 4. Sunderland, MA: Sinauer Associates.

Thompson, J. D., Gibson, T. J., Plewniak, F., Jeanmougin, F. \& Higgins, D. G. (1997). The CLUSTAL_X windows interface: flexible strategies for multiple sequence alignment aided by quality analysis tools. Nucleic Acids Res 25, 4876-4882. 